Research Paper

\title{
Effects of Zinc Supplementation on Plasma Copper/Zinc Ratios, Oxidative Stress, and Immunological Status in Hemodialysis Patients
}

\author{
Chih-Hung Guo ${ }^{1}$, Chia-Liang Wang ${ }^{\circledR}$ \\ 1. Micro-Nutrition Lab, Institute of Biomedical Nutrition, Hung Kuang University, Taichung 433, Taiwan, Republic of China; \\ 2. Department of Nephrology, Kuang-Tien General Hospital, Taichung 433, Taiwan, Republic of China.
}

$\triangle$ Corresponding author: E-mail: hollyspirit31@yahoo.com.tw (C-L. Wang). Tel: 886-4-2662-5111 ext. 2829; Fax: 886-4-2665-5050.

() Ivyspring International Publisher. This is an open-access article distributed under the terms of the Creative Commons License (http://creativecommons.org/ licenses/by-nc-nd/3.0/). Reproduction is permitted for personal, noncommercial use, provided that the article is in whole, unmodified, and properly cited.

Received: 2012.09.25; Accepted: 2012.12.19; Published: 2012.12.22

\begin{abstract}
Background: Patients undergoing hemodialysis (HD) have low plasma levels of zinc $(\mathrm{Zn})$, high plasma levels of copper $(\mathrm{Cu})$, and exhibit increased oxidative stress, inflammation, and immune abnormalities. We evaluated the effects of $\mathrm{Zn}$ supplementation on abnormal plasma $\mathrm{Cu} / \mathrm{Zn}$ ratios and clinical outcomes in HD patients.

Design and Methods: Patients on long-term HD with lower than normal plasma concentrations of $Z n(<80 \mathrm{mg} / \mathrm{dL})$ were randomized to receive daily oral $Z n$ supplements $(n=40)$ or no supplements $(n=25)$ for eight weeks. Age- and sex-matched healthy individuals served as a control group $(n=38)$. A number of clinical parameters were measured before and after the supplementation period.

Results: Compared with healthy subjects, patients had significantly elevated plasma $\mathrm{Cu}$ concentrations and $\mathrm{Cu} / \mathrm{Zn}$ ratios, as well as higher levels of oxidative stress and pro-inflammatory cytokines. Patients who received $\mathrm{Zn}$ supplements for eight weeks had higher plasma concentrations of $\mathrm{Zn}$ and lower concentrations of $\mathrm{Cu}$, along with reduced $\mathrm{Cu} / \mathrm{Zn}$ ratios, oxidative stress status, and inflammatory responses compared to patients who did not receive $Z n$. Patients receiving $Z n$ also showed significantly higher percentages of CD4 and CDI 9 lymphocytes, and elevated CD4/CD8 ratios.

Conclusions: $\mathrm{Zn}$ supplementation ameliorates abnormally high plasma $\mathrm{Cu} / \mathrm{Zn}$ ratios and may reduce oxidative stress, improve inflammatory status, and maintain immune function in patients undergoing long-term HD.
\end{abstract}

Key words: zinc supplement; copper/zinc ratios; oxidative stress; inflammation; immune function; hemodialysis patients.

\section{Introduction}

The morbidity and mortality risks of long-term hemodialysis (HD) can be attributed to many factors including wasting, inflammation, oxidative stress, and impaired immune responsiveness [1,2]. Patients on long-term HD have altered levels of essential trace minerals, predisposing them to such complications $[3,4]$. In particular, these patients have significantly decreased plasma or serum zinc ( $\mathrm{Zn}$ ) concentrations
$[5,6]$. Zn has antioxidant and anti-inflammatory properties and regulates T- and B-lymphocyte function, making it vital for the maintenance of normal immune function and resistance to infection $[7,8]$. HD patients have elevated levels of plasma copper $(\mathrm{Cu})$ and a markedly increased $\mathrm{Cu} / \mathrm{Zn}$ ratios $[9,10]$. $\mathrm{Cu}$ also acts as an antioxidant and anti-inflammatory agent and is required for immune function [11]; accordingly, 
increased plasma levels of $\mathrm{Cu}$ and elevated $\mathrm{Cu} / \mathrm{Zn}$ ratios are associated with nutritional abnormalities, oxidative stress, inflammation, and immune dysfunction $[9,10,12]$. The disruption of $\mathrm{Zn}$ and $\mathrm{Cu}$ levels has been suggested as a cause of clinical deterioration and adverse outcomes in HD patients. However, the mechanisms that mediate the homeostasis of $\mathrm{Zn}$ and $\mathrm{Cu}$ remain unknown.

Recent studies have shown that Zn supplementation increases serum $\mathrm{Zn}$ levels, improves the protein catabolic rate (PCR)[13], and raises cholesterol and low-density lipoprotein concentrations $[14,15]$ in HD patients. Plasma levels of C-reactive protein (CRP), a biomarker for inflammation, have been shown to be lower in patients treated with $\mathrm{Zn}$ supplements [3]. However, few studies have explored whether $\mathrm{Zn}$ supplementation normalizes the plasma $\mathrm{Cu} / \mathrm{Zn}$ ratios, decreases oxidative stress, or improves abnormalities of the immune response in these patients.

In the present preliminary investigation, we examined the effect of daily $\mathrm{Zn}$ supplementation on plasma concentrations of $\mathrm{Zn}$ and $\mathrm{Cu}$ and the $\mathrm{Cu} / \mathrm{Zn}$ ratio, oxidant and antioxidant status, pro-inflammatory cytokines, and immune responses in HD patients with lower than normal $\mathrm{Zn}$ levels.

\section{Materials and Methods}

\section{Patients}

Between January 2008 and June 2009, chronic renal failure patients on regular HD from the renal dialysis unit were enrolled. Patients with less than 6 months of follow-up, or patients who were more than 70 years of age were excluded. All patients received four-hour HD sessions three times per week with a high-flux membrane dialyzer. The dialysate flow rate was $500 \mathrm{~mL} / \mathrm{min}$ and the heparin was used as an anticoagulant. In addition, $\mathrm{Kt} / \mathrm{V}$ value equal to or greater than 1.2, as an index of treatment adequacy [16]. In all participants, none had gastrointestinal disorders, liver diseases, cancers, mental retardation or dementia, psychiatric illness, received immune suppressant drugs, and supplementation with natural herbs, antioxidants, vitamins/minerals, and fish oils. All patients were clinically stable condition as outpatients.

In clinical characteristics of patients, hypertension, ischemic heart disease, dyslipidemia, diabetes mellitus, and some drugs use were also recorded. Hypertension was defined as the presence of hypertension history. Ischemic heart disease was diagnosed based on the following criteria: angina pectoris, history of myocardial infarction, coronary artery bypass surgery, or percutaneous coronary intervention. The dyslipidemia was designated as fasting triglycerides of $200 \mathrm{mg} / \mathrm{dl}$ or greater or patients who were receiving medical treatment of hyperlipidemia. Diabetes mellitus was defined as present if patients were using insulin or oral hypoglycemic agents.

Patients with low plasma Zn concentrations (< $80 \mathrm{mg} / \mathrm{dL}$ ) were randomized, divided into two groups, and treated as follows: one group received oral supplementation with $11 \mathrm{mg}$ elemental $\mathrm{Zn}$ per day (78-mg Zn gluconate) for eight weeks $(n=40)$ and the control group received no supplements $(n=40)$. $\mathrm{Zn}$ was administered after dinner and the daily dose was guided by internationally recommended daily intakes [17] and our previous pre-clinical observations of a series plasma Zn determination after Zn supplementation. A third group of healthy volunteers $(\mathrm{n}=$ 40) of similar age and gender from the health evaluation center were also included. All subjects signed an informed consent statement prior to inclusion in the study. The study protocol was approved by the ethics in human research committee of Kuang Tien General Hospital.

\section{Biochemical Analyses}

Blood samples were drawn in the morning from participants between 07:30 and 09:00, after an overnight fast of $12 \mathrm{~h}$ at baseline and again after eight weeks of Zn treatment; pre-dialysis blood specimens were obtained from arterio-venous shunts. Plasma concentrations of albumin, hemoglobin, blood urea nitrogen (BUN), creatinine, triglyceride, and glucose were determined using a Hitachi 7050 automatic analyzer (Hitachi Corp., Tokyo, Japan). The Kt/V values and the protein equivalent of total nitrogen appearance normalized to dry body weight (nPNA) that is an estimate of protein intake [18], were determined in HD patients. Urine was collected from all of the patients before the start of dialysis therapy. In addition, the estimated glomerular filtration rate (eGFR) was obtained using the Modification of Diet in Renal Disease (MDRD) study equation [19].

\section{Determination of Trace Minerals}

The concentrations of plasma $\mathrm{Zn}$ and $\mathrm{Cu}$ were measured by flame atomic absorption spectrophotometer (932 plus, GBC, Australia) using an air-acetylene flame without background correction at 213.9 and $324.71 \mathrm{~nm}$, respectively. Triplicate absorbance readings were taken for each sample in the peak-height mode. Samples were digested in a $\mathrm{H}_{2} \mathrm{O}_{2} / \mathrm{HNO}_{3}$ mixture in a start $\mathrm{D}$ microwave-assisted digestion system (Milestone Microwave Labstation ETHOSD) and subsequently brought up the volume with double deionized water. Accuracy of this meth- 
od was confirmed by comparing to serum reference materials (level 2, NO0371, Seronorm, Nycomed, Oslo, Norway).

\section{Measurement of Oxidative Stress Status}

The extent of lipid peroxidation was determined by assaying the formation of malondialdehyde (MDA). Plasma samples were mixed with $3 \%$ sodium dodecyl sulfate, $0.1 \mathrm{~N} \mathrm{HCl}, 10 \%$ phosphotungstic acid, and thiobarbituric acid, and then incubated at $95{ }^{\circ} \mathrm{C}$ for $60 \mathrm{~min}$. The n-butanol was added and the mixture was shaken vigorously. After centrifugation at 12,000 $\mathrm{x} \mathrm{g}$ and $4{ }^{\circ} \mathrm{C}$ for $15 \mathrm{~min}$, the absorbance of the upper layer was read at $530 \mathrm{~nm}$ with excitation at $485 \mathrm{~nm}$ [10].

The erythrocyte pellets were washed three times with cold isotonic saline. Lysate of erythrocytes was prepared by adding distilled water and keeping the mixture at $4^{\circ} \mathrm{C}$ for $15 \mathrm{~min}$. Erythrocyte superoxide dismutase (SOD) enzyme activities were determined as indices of anti-oxidative capacity. The $\mathrm{Cu}, \mathrm{Zn}$-SOD activity was determined with SOD assay kits (Cayman, Ann Arbor, Michigan, USA); one unit was defined as the amount of enzyme necessary to produce $50 \%$ dismutation of the superoxide radicals. The absorbance was measured at $450 \mathrm{~nm}$ using a Multiskan Ascent microplate spectro- photometer (Thermo Labsystems). The activity of SOD was expressed in unit per gram of hemoglobin $(\mathrm{U} / \mathrm{g} \mathrm{Hb})$.

\section{Measurement of Inflammation Status}

In plasma, the systemic marker of inflammation, high-sensitively C-reactive protein (hs-CRP) concentrations were measured using the hs-CRP ELISA kit (DRG Instrument $\mathrm{GmbH}$, Marburg, Germany). In addition, inflammatory cytokines tumor necrosis factor- $\alpha$ (TNF- $\alpha)$ (\#88-7346, eBioscience, San Diego, CA, USA) and IL-1 $\beta$ (\#88-7010-86, ELISA Ready-SET-Go, eBioscience) were measured. Briefly, plasma samples were added to the wells and incubated with anti-TNF- $\alpha$ or IL-1 $\beta$ antibodies for overnight. Combined avidin-HRP and substrate solution was added to each well and was incubated at room temperature. The absorbance at $450 \mathrm{~nm}$ was measured, and readings were interpolated into the standard curve.

\section{Determination of $\beta$-carotene, Vitamin $C$ and $E$}

Plasma concentrations of $\beta$-carotene and vitamin $\mathrm{E}$ were measured by reversed- phase HPLC (LabAlliance, HPLC Pumps, Systems \& Accessories)[20]. Briefly, samples were extracted with n-hexane/ethanol containing a-tocopheryl acetate as an internal standard. The n-hexane layer was separated and evaporated to dryness. The residue was re-dissolved in the methanol/acetonitrile/ tetrahydrofuran mobile phase. A Gemini C18 column (250 x $4.6 \mathrm{~mm}, 5 \mu \mathrm{m})$ (Phenomenex) was used and peaks were detected at wavelengths of $450 \mathrm{~nm}$ for $\beta$-carotene and $295 \mathrm{~nm}$ for vitamin E. For plasma vitamin $C$ determination, samples were immediately treated with $4 \%$ metaphosphoric acid/ dithiothreitol as a stabilizer. The product was then coupled to o-phenylenediamine to produce a chromophore, and absorbance was measured at $340 \mathrm{~nm}$ [21].

\section{Determination of Immunologic Parameters}

Peripheral blood B- or T-lymphocytes of all subjects were stained with the following monoclonal antibodies, which conjugated with fluorescein isothiocyanate (FITC) and phycoerythrin (PE): CD3 FITC/ CD4 PE/CD8 PE/CD19 PE (eBioscience). Briefly, $100 \mu \mathrm{L}$ of whole blood were incubated with 20 $\mu \mathrm{L}$ of monoclonal antibody reagent for $15 \mathrm{~min}$ in the dark at room temperature. Following leukocyte fixation and erythrocyte lysis with CyLyse lysing reagent kit (Partec, GMBH, Münster, Germany), the percentages of lymphocyte subsets were determined using a Partec CyFlow ML flow cytometer (Partec, $\mathrm{GmbH}$ ).

\section{Statistical analysis}

Each value was expressed as the mean \pm SD or medians (inter-quartile range), depending on the normality of data distribution (Shapiro-Wilk test). Comparisons of different variables were made by chi-square test, student's $t$-test, pair $t$-test, one-way analysis of variance (ANOVA), or Kruskal-Wallis ANOVA, as appropriate. A two-tailed $p$ value $<0.05$ was considered statistically significant.

\section{Results}

\section{Clinical Data}

A total of 40 control group patients who received no supplements were initially included. However, 15 patients were excluded due to incomplete baseline or follow up information $(n=3)$, severe cold symptoms $(n=7)$, or the use of additional herb or vitamin B complex during study period $(n=5)$. All data were analysis for the remaining 25 patients. Two participants in the healthy group were also excluded from the analysis due to insufficient sample.

As shown in Table 1, HD patients had significantly higher concentrations of BUN and plasma creatinine than healthy controls $(p<0.05)$, but had lower concentrations of hemoglobin and albumin. The concentrations of all other variables were comparable between the two patient groups. There were no particular subjective symptoms seen in the Zn-treated 
patients. After eight weeks, HD patients receiving $\mathrm{Zn}$ supplementation had markedly higher nPNA, hemoglobin, and albumin concentrations, as well as higher eGFR, than patients who did not receive $\mathrm{Zn}$ supplements (Figure 1). The Zn-treated patients had maintained a stable weight over the study periods; whereas weight loss in patients who did not receive $\mathrm{Zn}$ was found.

\section{Trace Mineral Status}

At baseline, patients had significantly lower plasma concentrations of $\mathrm{Zn}$, higher plasma concentrations of $\mathrm{Cu}$, and increased plasma $\mathrm{Cu} / \mathrm{Zn}$ ratio than the healthy subjects (Table 2 ). In the $\mathrm{Zn}$ supplementation group, there was a trend towards normalization of these parameters after the eight-week treatment period. Patients who did not receive Zn, however, continued to exhibit markedly lower plasma concentrations of $\mathrm{Zn}$ and higher $\mathrm{Cu}$ and higher $\mathrm{Cu} / \mathrm{Zn}$ ratio compared to the healthy controls (Figure 2).

\section{Oxidative Stress Status}

The plasma contents of oxidative product MDA were considerably increased in HD patients compared to healthy subjects (Table 2). Further, a significant reduction in the activity of erythrocyte SOD in these patients was observed. After Zn supplementation, HD patients showed marked decreases in the levels of oxidative products together with an elevation of SOD activity compared to the control patients (Figure 1). However, a progressive increase in plasma oxidative product was observed in patients who did not receive Zn.

\section{Inflammatory Status}

CRP is a sensitive biomarker of inflammatory activity. HD patients had significantly higher plasma concentrations of hs-CRP than the healthy subjects (Table 2). Increased plasma concentrations of the pro-inflammatory cytokines TNF- $\alpha$ and IL-1 $\beta$ were also observed in dialysis patients. After the treatment period, the Zn-supplemented patients had significantly decreased concentrations of hs-CRP, TNF- $\alpha$, and IL-1 $\beta$ compared to patients not receiving $\mathrm{Zn}$ supplementation (Figure 2).

\section{$\beta$-carotene, Vitamin $\mathbf{C}$ and $\mathbf{E}$ Concentrations}

Plasma concentrations of $\beta$-carotene, vitamin $C$ and $\mathrm{E}$, biomarkers of antioxidant and immune function, were significantly lower in HD patients than in the healthy subjects (Table 2). After the treatment period, the Zn-supplemented patients had markedly higher $\beta$-carotene, vitamin $\mathrm{C}$ and $\mathrm{E}$ concentrations compared with patients not receiving $\mathrm{Zn}$ supplementation (Figure 3).

\section{Immunologic Variables}

The percentages of circulating CD3 and CD4 T-lymphocytes in patients undergoing HD were significantly lower than in healthy subjects (Table 2), as were the ratio of CD4 to CD8 subsets and the percentage of CD19 B-lymphocytes. After eight weeks, patients receiving $\mathrm{Zn}$ supplementation had markedly higher percentages of CD4 and CD19 lymphocytes, and non-significantly increased CD4/CD8 ratios $(p=$ $0.09)$, compared with patients who did not receive $\mathrm{Zn}$ (Figure 3).

\section{Correlation between $\mathrm{Cu} / \mathrm{Zn}$ ratio, oxidative stress, and inflammation}

After HD patients receiving Zn supplementation, plasma $\mathrm{Cu} / \mathrm{Zn}$ ratio was positively correlated with the concentration of MDA ( $r=0.346, p=0.03)$. There were also positive relationships between plasma $\mathrm{Cu} / \mathrm{Zn}$ ratio and hs-CRP $(r=0.354, p=0.03)$, TNF- $\alpha(r=0.359, p=0.02)$, and IL-1 $\beta(r=0.218, p=$ $0.18)$ (data not shown).

Table I. Baseline characteristics of the study group subjects $1,2,3$

\begin{tabular}{llll}
\hline & Zinc supplement patients $(\mathrm{n}=40)$ & Control group patients $(\mathrm{n}=25)$ & Healthy subjects $(\mathrm{n}=38)$ \\
\hline Age $(\mathrm{yrs})$ & $59 \pm 10$ & $61 \pm 8$ & $60 \pm 5$ \\
Gender $(\mathrm{M} / \mathrm{F})$ & $22 / 18$ & $14 / 11$ & $20 / 18$ \\
Dialysis duration (months) & $62 \pm 12$ & $64 \pm 10$ & - \\
Body mass index, BMI (kg/m²) & & & $24 \pm 2$ \\
Beginning of study & $23 \pm 2$ & $22 \pm 3$ & - \\
End of study & $24 \pm 3^{\mathbf{b}}$ & $21 \pm 3^{\mathbf{a}}$ & $18(9-26)^{\mathbf{a}}$ \\
BUN (mg/dl) & $69(61-80)^{\mathbf{b}}$ & $67(56-87)^{\mathbf{b}}$ & $1.8 \pm 0.6^{\mathbf{a}}$ \\
Creatinine $(\mathrm{mg} / \mathrm{dl})$ & $10.3 \pm 3.0^{\mathbf{b}}$ & $9.3 \pm 2.0^{\mathbf{b}}$ & $4.7(4.0-5.4)^{\mathbf{b}}$ \\
Albumin $(\mathrm{mg} / \mathrm{dl})$ & $3.2(2.9-3.7)^{\mathbf{a}}$ & $3.4(2.9-3.6)^{\mathbf{a}}$ & \\
\hline
\end{tabular}




\begin{tabular}{|c|c|c|c|}
\hline Hemoglobin (gm\%) & $9.6 \pm 0.8^{\mathbf{a}}$ & $9.7 \pm 0.8^{\mathbf{a}}$ & $16.8 \pm 1.1^{b}$ \\
\hline nPNA (g/kg/day) & $0.9 \pm 0.3$ & $1.0 \pm 0.3$ & - \\
\hline eGFR $\left(\mathrm{mL} / \mathrm{min} / 1.73 \mathrm{~m}^{2}\right)$ & $4.8(4.0-7.0)$ & $5.3(4.8-6.5)$ & - \\
\hline $\mathrm{Kt} / \mathrm{V}$ (/week) & $1.3 \pm 0.1$ & $1.4 \pm 0.1$ & - \\
\hline Diabetes mellitus (\%) & 30 & 32 & - \\
\hline Hypertension (\%) & 10 & 8 & - \\
\hline Dyslipidemia (\%) & 13 & 12 & - \\
\hline Ischemic heart disease (\%) & 30 & 32 & \\
\hline \multicolumn{4}{|l|}{ Other drugs use } \\
\hline Insulin (\%) & 10 & 8 & - \\
\hline Sulfonylurea (\%) & 20 & 24 & - \\
\hline Statin (\%) & 0 & 0 & - \\
\hline $\mathrm{Ca}+2$ channel antagonists $(\%)$ & 25 & 23 & - \\
\hline$\beta$-blocker (\%) & 15 & 13 & - \\
\hline Triglyceride (mg/dL) & $136 \pm 106$ & $129 \pm 96$ & $130 \pm 45$ \\
\hline Fasting glucose (mg/dL) & $109 \pm 9$ & $103 \pm 8$ & $94 \pm 9$ \\
\hline Smoking (\%) & 5 & 4 & 5 \\
\hline Alcohol consumption (\%) & 0 & 0 & 0 \\
\hline
\end{tabular}

Table 2. Baseline levels of micronutrients, oxidative stress, inflammatory status, and immune function of the study group subjects $1,2,3$.

\begin{tabular}{llll}
\hline & Zinc supplement patients $(\mathrm{n}=40)$ & \multicolumn{1}{c}{ Control group patients $(\mathrm{n}=25)$} & Healthy subjects $(\mathrm{n}=38)$ \\
\hline $\mathrm{Zn}(\mathrm{ug} / \mathrm{mL})$ & $0.4(0.2-0.5)^{\mathbf{a}}$ & $0.4(0.3-0.5)^{\mathbf{a}}$ & $0.9(0.8-1.3)^{\mathbf{b}}$ \\
$\mathrm{Cu}(\mathrm{ug} / \mathrm{mL})$ & $0.9 \pm 0.1^{\mathbf{b}}$ & $0.9 \pm 0.2^{\mathbf{b}}$ & $0.6 \pm 0.2^{\mathbf{a}}$ \\
$\mathrm{Cu} / \mathrm{Zn}$ ratios & $2.4(1.8-3.7)^{\mathbf{b}}$ & $2.5(2.1-3.4)^{\mathbf{b}}$ & $0.7(0.6-0.9)^{\mathbf{a}}$ \\
$\beta$-carotene $(\mathrm{\mu g} / \mathrm{mL})$ & $0.9(0.6-1.3)^{\mathbf{a}}$ & $0.7(0.6-1.0)^{\mathbf{a}}$ & $2.5(2.0-2.9)^{\mathbf{b}}$ \\
Vitamin C $(\mu \mathrm{g} / \mathrm{mL})$ & $2.5(1.5-4.0)^{\mathbf{a}}$ & $2.5(1.7-4.1)^{\mathbf{a}}$ & $12.1(8.4-15.4)^{\mathbf{b}}$ \\
Vitamin E $(\mu \mathrm{g} / \mathrm{mL})$ & $4.5 \pm 1.9^{\mathbf{a}}$ & $4.4 \pm 1.8^{\mathbf{a}}$ & $12.2 \pm 1.7^{\mathbf{b}}$ \\
MDA $(\mathrm{nmol} / \mathrm{mL})$ & $6.5 \pm 2.0^{\mathbf{b}}$ & $6.5 \pm 1.3^{\mathbf{b}}$ & $2.6 \pm 1.3^{\mathbf{a}}$ \\
SOD $(\mathrm{U} / \mathrm{g} \mathrm{Hb})$ & $1478 \pm 181^{\mathbf{a}}$ & $1507 \pm 207^{\mathbf{a}}$ & $2300 \pm 336^{\mathbf{b}}$ \\
hs-CRP $(\mathrm{ng} / \mathrm{mL})$ & $10.7(6.2-17.3)^{\mathbf{b}}$ & $9.6(4.8-13.5)^{\mathbf{b}}$ & $1.7(0.5-2.4)^{\mathbf{a}}$ \\
TNF- $\alpha(\mathrm{pg} / \mathrm{mL})$ & $63.0(38.4-121.2)^{\mathbf{b}}$ & $74.0(40.3-99.1)^{\mathbf{b}}$ & $12.5(8.6-17.0)^{\mathbf{a}}$ \\
IL-1 $\beta(\mathrm{pg} / \mathrm{mL})$ & $74.3(34.6-102.0)^{\mathbf{b}}$ & $74.8(52.9-105.7)^{\mathbf{b}}$ & $7.2(5.4-8.9)^{\mathbf{a}}$ \\
CD3 $(\%)$ & $53.9 \pm 9.9^{\mathbf{a}}$ & $54.5 \pm 7.6^{\mathbf{a}}$ & $61.2 \pm 3.6^{\mathbf{b}}$ \\
CD4 $(\%)$ & $30.0 \pm 7.2^{\mathbf{a}}$ & $32.2 \pm 7.8^{\mathbf{a}}$ & $40.2 \pm 2.5^{\mathbf{b}}$ \\
CD8 $(\%)$ & $20.7 \pm 6.3$ & $24.4 \pm 7.2$ & $22.7 \pm 5.3$ \\
CD4/CD8 ratio & $1.5(1.2-1.8)^{\mathbf{a}}$ & $1.4(1.0-2.0)^{\mathbf{a}}$ & $2.0(1.7-2.3)^{\mathbf{b}}$ \\
CD19 $(\%)$ & $8.7(6.4-11.7)^{\mathbf{a}}$ & $7.6(5.1-12.6)^{\mathbf{a}}$ & $12.4(10.0-12.7)^{\mathbf{b}}$
\end{tabular}

${ }^{1}$ Values are mean $\pm \mathrm{SD}$ or medians (inter-quartile range). ${ }^{2}$ Values in the same row with different superscripts are significantly different $(p<0.05) .{ }^{3} \mathrm{Zn}=\mathrm{zinc} ; \mathrm{Cu}$

$=$ copper; $\mathrm{MDA}=$ malondialdehyde; $\mathrm{SOD}=$ superoxide dismutase; TNF- $\alpha=$ tumor necrosis factor- $\alpha$; IL-1 $\beta=$ interleukin- $1 \beta ; \mathrm{CD} 3=$ mature T lymphocytes; CD19

$=\mathrm{B}$-lymphocyte antigen; $\mathrm{CD} 4 / \mathrm{CD} 8=$ ratios of helper T-lymphocytes to cytotoxic T-lymphocytes. 

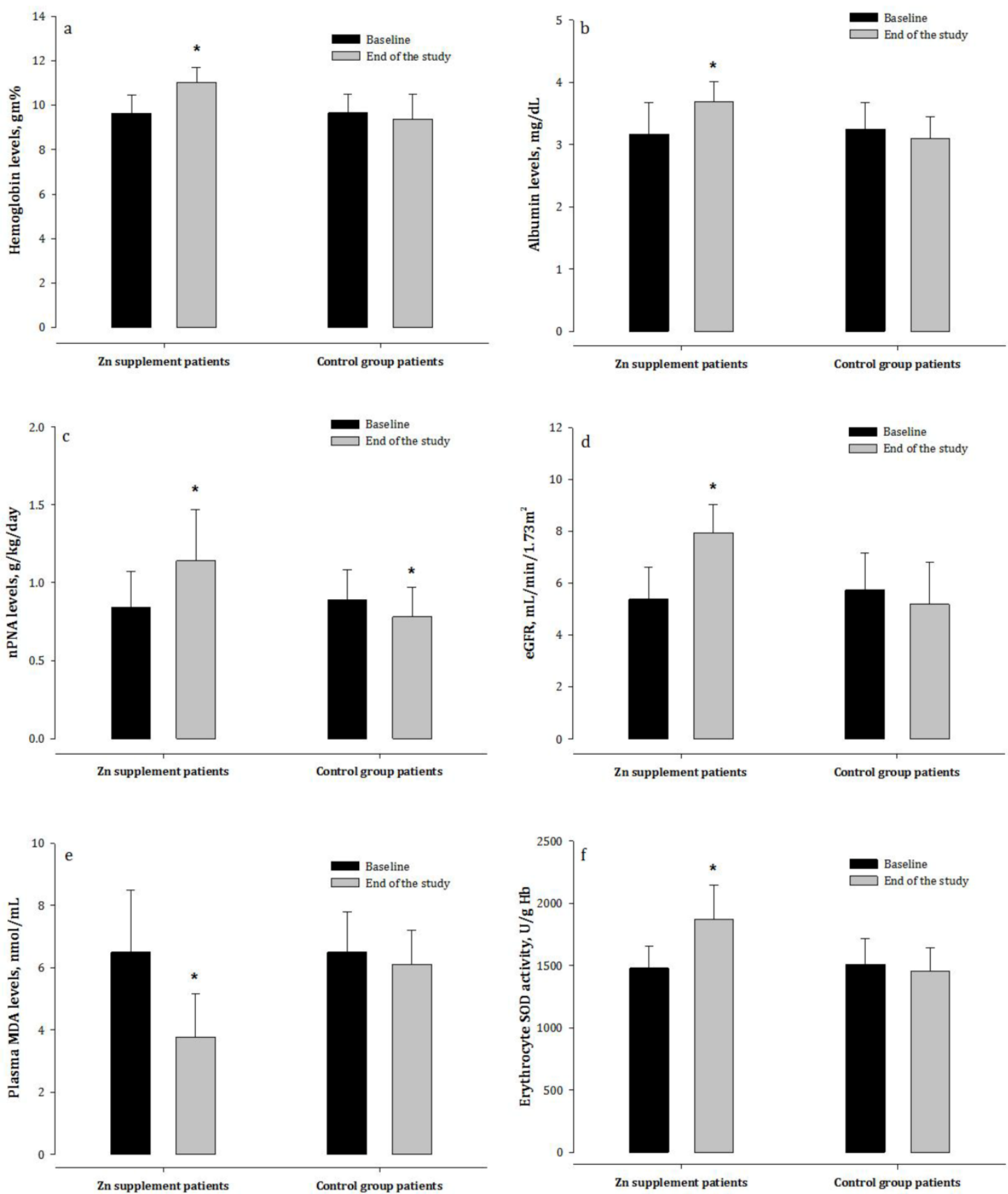

Figure I. Biochemical observations in hemodialysis patients treated with or not treated with zinc supplementation. nPNA = normalized protein equivalent of nitrogen appearance; eGFR = estimated glomerular filtration rates; MDA = malondialdehyde; erythrocyte SOD = superoxide dismutase. 

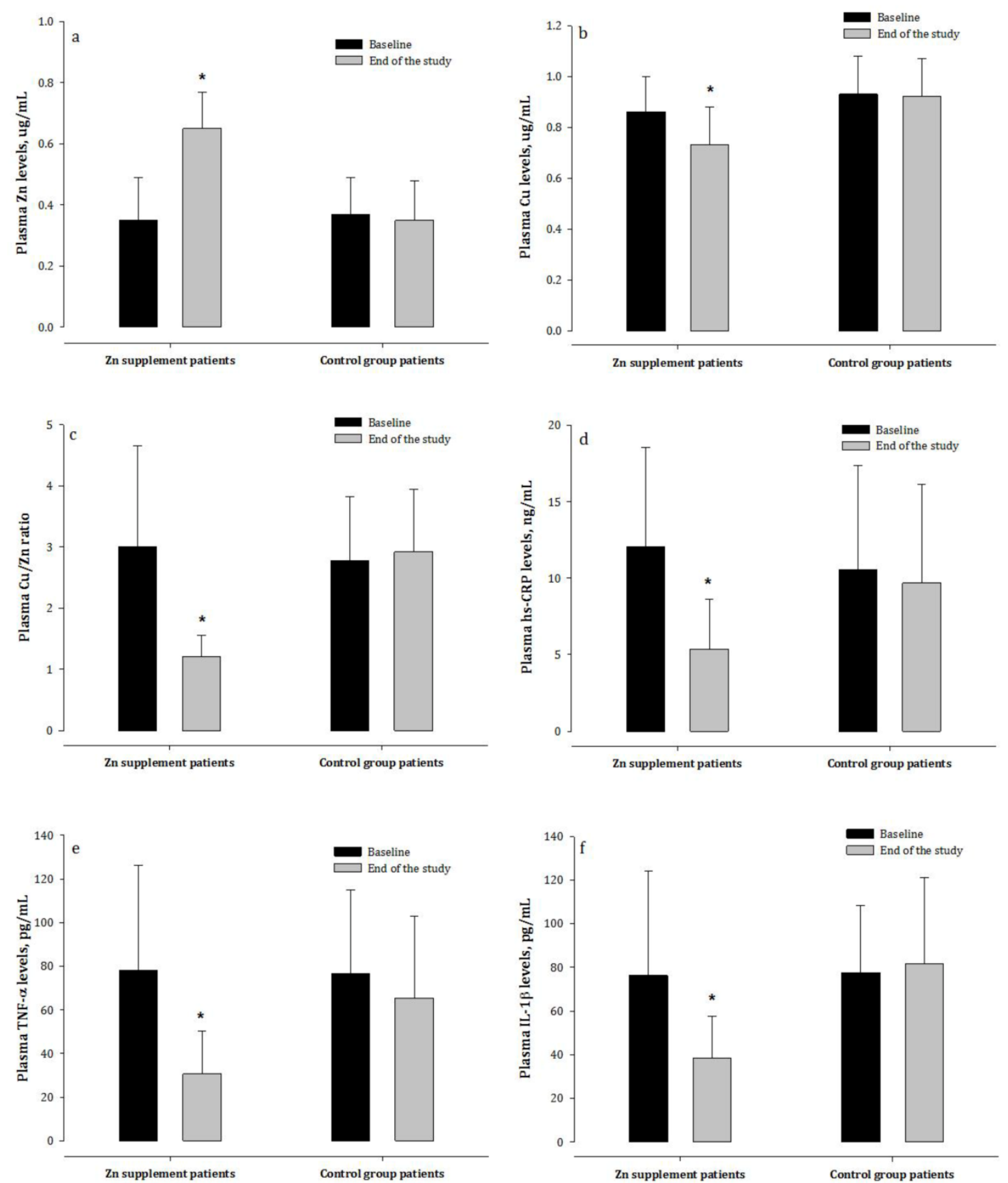

Figure 2. Changes in plasma levels of $\mathrm{Zn}, \mathrm{Cu}, \mathrm{hs}-\mathrm{CRP}$, and pro-inflammatory cytokines in hemodialysis patients treated with and not treated with zinc supplementation. $\mathrm{Zn}=$ zinc; $\mathrm{Cu}=$ copper; hs-CRP = high-sensitivity CRP; TNF- $\alpha=$ tumor necrosis factor- $\alpha$; IL-I $\beta=$ interleukin I $\beta$. 

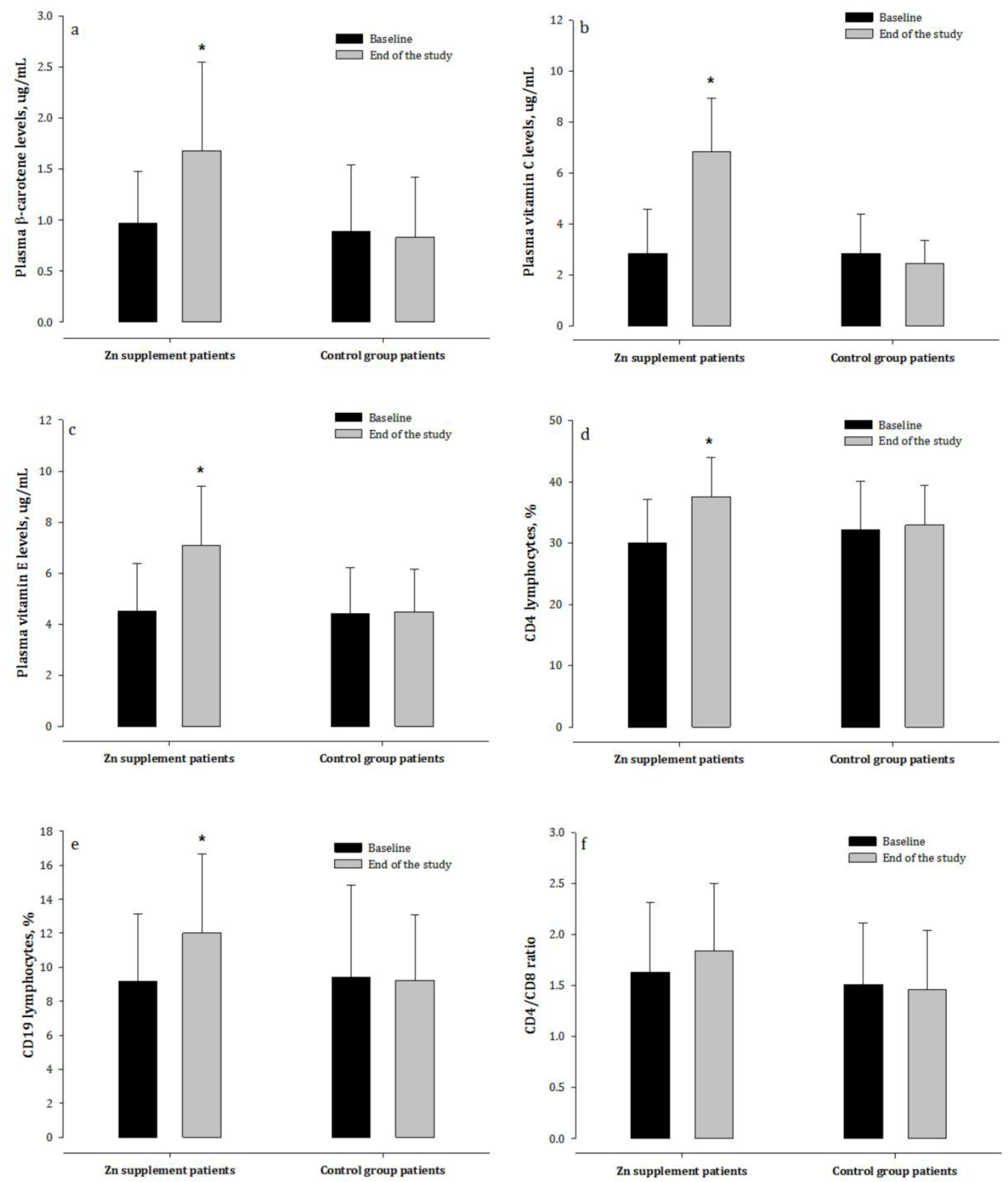

Figure 3. Changes in plasma vitamin status and immune index in hemodialysis patients treated with and not treated with zinc supplementation. $C D 4=T$-helper cells; $C D 8=$ cytotoxic $T$ cells; $C D 19=$ antigen expressed on the surface of $B$ cells.

\section{Discussion}

Our preliminary observation that HD patients with decreased plasma Zn levels had elevated plasma $\mathrm{Cu}$ concentrations, are consistent with the results of previous studies $[22,23]$. Low plasma $\mathrm{Zn}$ concentrations are thought to result from $\mathrm{Zn}$ removal during dialysis treatment, decreased albumin levels, and reduced gastrointestinal absorption of $\mathrm{Zn}$ [1]. Moreover, increased expression of intracellular metallothioneins following oxidative stress or up-regulation of Zn-importing proteins by pro-inflammatory cytokines can reduce the plasma Zn levels [24]. In contrast, the release of $\mathrm{Cu}$ during tissue damage mediated by inflammation and impaired hepatic metabolism of $\mathrm{Cu}$ may account for increased plasma $\mathrm{Cu}$ concentrations; increased $\mathrm{Cu}$ levels are associated with elevated oxidative stress. Thus, HD patients are at higher risk of developing an imbalance of plasma $\mathrm{Zn}$ and $\mathrm{Cu}$, which may increase the inflammatory process and oxidative 
stress.

Previous investigation has found that dialysis patients have abnormally increased plasma $\mathrm{Cu} / \mathrm{Zn}$ ratios and elevated plasma concentrations of hs-CRP [10], both of which associated with the development of renal failure [25]. In the present study, high plasma $\mathrm{Cu} / \mathrm{Zn}$ ratios and increased inflammatory markers including hs-CRP, TNF- $\alpha$, and IL- $1 \beta$ concentrations in HD patients were observed. Elevated levels of hs-CRP have been associated with endothelial injury and pro-inflammatory cytokine release, and thus lead to glomerular damage and progressive loss of kidney function [26,27]. TNF- $\alpha$ and IL-1 $\beta$ also induce expression of leukocyte adhesion molecules and chemokines in progressive renal injury $[28,29]$. The present finding indicated that high plasma $\mathrm{Cu} / \mathrm{Zn}$ ratios reflect the abnormal $\mathrm{Zn}$ and $\mathrm{Cu}$ homeostasis, and would be a clinical predictor for their inflammatory status.

The effects of Zn supplementation (50-100 $\mathrm{mg}$ of elemental $\mathrm{Zn}$ from $\mathrm{Zn}$ sulfate for 42 or 90 days) on improving serum $\mathrm{Zn}$ and CRP concentrations in HD patients have been examined from small observational studies [3,14]. Further supporting the findings of these studies, our results showed that $\mathrm{Zn}$ administration $(10 \mathrm{mg}$ of elemental $\mathrm{Zn}$ from $\mathrm{Zn}$ gluconate for eight weeks) in HD patients resulted in significantly elevated plasma $\mathrm{Zn}$ concentrations, decreased $\mathrm{Cu}$ concentrations and $\mathrm{Cu} / \mathrm{Zn}$ ratios, and lower concentrations of hs-CRP and pro-inflammatory cytokines. Attenuated renal dys- function was also found in these patients on HD, although the increase in eGFR of approximately $5 \mathrm{ml} / \mathrm{min}$ was not clinically significant. These findings suggest that $\mathrm{Zn}$ treatment diminishes the inflammatory response and thus may be beneficial in patients with renal failure.

Furthermore, inflammation may cause malnutrition and increase the risk of poor outcomes in dialysis patients $[30,31]$. Inverse correlations have been noted in dialysis patients between plasma hs-CRP and nutritional status and the efficacy of dialysis [27,32]. Inflammatory process also increases urinary albumin excretion, and induces oxidation of albumin and hemoglobin $[33,34]$. Improvements in nutritional status can attenuate inflammation and oxidative stress, which correlate with the decline of renal function [35]. We previously showed that increased plasma $\mathrm{Cu} / \mathrm{Zn}$ ratios was associated with decreased plasma albumin and hemoglobin levels (well-known markers of nutritional status), although both albumin and hemoglobin concentrations were influenced by numerous factors [10]. Zn deficiency has been associated with diminished appetite and hyperleptinemia [36]. Malnutrition in HD patients may result from low plasma Zn levels, in which case $\mathrm{Zn}$ supplementation will be needed to prevent progressive malnutrition [37]. Zn supplementation may improve the acuity of taste and smell, increase food intake, and reduce protein-energy wasting [13-15,38]. In the present preliminary study, dietary intake data before and after Zn supplementation were not available, which we consider to be a limitation. Patients receiving $\mathrm{Zn}$ showed markedly decreased plasma $\mathrm{Cu} / \mathrm{Zn}$ ratios, an increase in $\mathrm{nPNA}$, as well as markedly higher plasma concentrations of hemoglobin and albumin. Our observations suggest that $\mathrm{Zn}$ administration improves the oxidative stress and inflammatory process, and may therefore be effective in improving the nutritional status of HD patients.

Chronic inflammation markedly disturbs the immune competence of patients undergoing long-term HD [39]. Abnormalities in T-cell and B-cell function are well documented in these patients, and are known to increase morbidity and mortality [40]. Dialysis patients with decreased CD4/CD8 ratios and lower CD19 counts tend to suffer from malnutrition and inflammation, and have unfavorable outcomes [41]. An imbalanced $\mathrm{Cu} / \mathrm{Zn}$ ratio has also been associated with poor immune system status [10]. Zn deficiency is associated with significantly decreased CD4/CD8 ratio and lower B-cells numbers [42]. In contrast, excessive $\mathrm{Cu}$ levels may significantly decrease the circulating CD4/CD8 ratio and activity of natural killer (NK) cells [43]. In the present study, patients who received Zn supplementation had higher CD4/CD8 ratios and percentages of CD19 cells than the control patients. These observations suggest that $\mathrm{Zn}$ supplementation would be beneficial for immune function in these patients with low plasma Zn concentrations.

Significantly decreased non-enzymatic antioxidant $\beta$-carotene, vitamins $C$, and vitamin $E$ levels in HD patients were observed. Recent studies have shown that these micronutrients can modulate the immune responses. HD patients are particularly prone to vitamin $\mathrm{C}$ deficiency because of dietary restrictions, limited absorption, poor nutritional status, and uremic toxicity. Plasma vitamin C levels are positively associated with serum albumin concentrations and negatively associated with hs-CRP levels [44]. Dietary Zn deficiency significantly decreases plasma levels of vitamin E [45]. In addition, there was a significant increase in the number of NK cells by $\beta$-carotene [46]. Significant negative correlations between renal dysfunction and oxidative stress with plasma $\beta$-carotene levels were observed in patients receiving dialysis treatment [47]. In the present investigation, patients who received $\mathrm{Zn}$ supplements had a trend toward increased plasma $\beta$-carotene, vitamin $C$ 
and E levels. Zn supplementation may improve the intake of foods that are high sources of these vitamins, and prevent the depletion of micronutrients attributed to high oxidative stress and inflammation. Thus, $\mathrm{Zn}$ administration has the potential to reduce the risk of those micronutrients loss, increase redox balance, and therefore can help to improve the immune function.

Though the present pilot investigation is not a double-blind placebo-controlled trial, the results show that administration of low doses of $\mathrm{Zn}$ decreased high plasma $\mathrm{Cu} / \mathrm{Zn}$ ratios in chronic HD patients and contributed to reducing inflammation and oxidative stress, improve nutritional status, and having a beneficial effect on immune function. Further large-scale studies will be needed to clarify the effects and consider the amounts of $\mathrm{Zn}$ supplementation in patients. Based on our study, it is concluded that Zn supplementation may be necessary to ameliorate their clinical outcomes in chronic HD patients with lower than normal $\mathrm{Zn}$ levels.

\section{Competing interests} to declare.

The authors do not have any conflicts of interest

\section{Acknowledgments}

Research supported in part by a grant from Kuang-Tien General Hospital, Taichung, Taiwan.

\section{References}

1. Guo $\mathrm{CH}$, Wang CL, Chen PC. Micronutrient metabolism in hemodialysis patients. In: Maria Goretti Penido, ed. Hemodialysis-different aspects. Croatia: InTech; 2011: 173-204.

2. Ozen KP, Asci G, Gungor O, et al. Nutritional state alters the association between free triiodothyronine levels and mortality in hemodialysis patients. Am J Nephrol. 2011;33:305-12.

3. Rashidi AA, Salehi M, Piroozmand A, Sagheb MM. Effects of zinc supplementation on serum zinc and C-reactive protein concentrations in hemodialysis patients. J Ren Nutr. 2009;19:475-8.

4. Guo CH, Wang CL, Chen PC, Yang TC. Linkage of some trace elements, peripheral blood lymphocytes, inflammation, and oxidative stress in ESRD patients undergoing either hemodialysis or peritoneal dialysis. Periton Dialysis Int. 2011; 31:583-91.

5. Sahin H, Uyanik F, Inanç N, Erdem O. Serum zinc, plasma ghrelin, leptin levels, selected biochemical parameters and nutritional status in malnourished hemodialysis patients. Biol Trace Elem Res. 2009;127:191-9.

6. Rucker D, Thadhani R, Tonelli M. Trace element status in hemodialysis patients. Semin Dial. 2010;23:389-95.

7. Prasad AS. Zinc: role in immunity, oxidative stress and chronic inflammation. Curr Opin Clin Nutr Metab Care. 2009;12:646-52.

8. Fischer Walker C, Black RE. Zinc and the risk for infectious disease. Annu Rev Nutr. 2004;24:255-75.

9. Ikee R, Tsunoda M, Sasaki N, Sato N, Hashimoto N. Clinical factors associated with serum copper levels and potential effect of sevelamer in hemodialysis patients. Int Urol Nephrol. 2012; [Epub ahead of print].

10. Guo $\mathrm{CH}$, Chen PC, Yeh MS, Hsiung DY, Wang CL. Cu/Zn ratios are associated with nutritional status, oxidative stress, inflammation and immune abnormalities in patients on peritoneal dialysis. Clin Biochem. 2011; 44:275-80.

11. Maggini S, Wintergerst ES, Beveridge S, Hornig DH. Selected vitamins and trace elements support immune function by strengthening epithelial barriers and cellular and humoral immune responses. Brit J Nutr. 2007; 98(suppl 1): S29-S35.

12. Navarro-Alarcon M, Reyes-Pérez A, Lopez-Garcia H, Palomares-Bayo M, Olalla- Herrera M, Lopez-Martinez MC. Longitudinal study of serum zinc and copper levels in hemodialysis patients and their relation to biochemical markers. Biol Trace Elem Res. 2006;113:209-22.

13. Jern NA, VanBeber AD, Gorman MA, Weber CG, Liepa GU, Cochran $\mathrm{CC}$. The effects of zinc supplementation on serum zinc concentration and protein catabolic rate in hemodialysis patients. J Ren Nutr. 2000;10:148-53.

14. Chevalier CA, Liepa G, Murphy MD, et al. The effects of zinc supplementation on serum zinc and cholesterol concentrations in hemodialysis patients. J Ren Nutr. 2002;12:183-9.

15. Roozbeh J, Hedayati P, Sagheb MM, et al. Effect of zinc supplementation on triglyceride, cholesterol, LDL, and HDL levels in zinc-deficient hemodialysis patients. Ren Fail. 2009;31:798-801.

16. Daurgidas JT, Blake PG, Ing TS. Handbook of Dialysis; 4 ed. Philadelphia: Lippincott. 2007: 774.

17. Food and Nutrition Board: Institute of Medicine. Dietary Reference Intakes for Vitamin A, Vitamin K, Arsenic, Boron, Chromium, Copper, Iodine, Iron, manganese, Molybdenum, Nickel, Silicon, Vanadium and Zinc. Washington, DC: National Academy Press, 2001.

18. Bergström J, Heimbürger $\mathrm{O}$, Lindholm B. Calculation of the protein equivalent of total nitrogen appearance from urea appearance. Which formulas should be used? Perit Dial Int. 1998;18:467-73.

19. Levey AS, Bosch JP, Lewis JB, Greene T, Rogers N, Roth D. A more accurate method to estimate glomerular filtration rate from serum creatinine: a new prediction equation. Ann Intern Med. 1999;130:461-70.

20. Borel P, Grolier P, Mekki N, et al. Low and high responders to pharmacological doses of beta-carotene: proportion in the population, mechanisms involved and consequences on beta-carotene metabolism. J Lipid Res. 1998;39:2250-60.

21. Lee W, Roberts SM, Labbe RF. Ascorbic acid determination with an automated enzymatic procedure. Clin Chem. 1997;43:154-7.

22. Tonelli M, Wiebe N, Hemmelgarn B, et al. Trace elements in hemodialysis patients: a systematic review and meta-analysis. BMC Med. 2009;7:25.

23. Dashti-Khavidaki S, Khalili H, Vahedi SM, Lessan-Pezeshki M. Serum zinc concentrations in patients on maintenance hemodialysis and its relationship with anemia, parathyroid hormone concentrations and pruritus severity. Saudi J Kidney Dis Transpl. 2010;21:641-5.

24. Liuzzi JP, Lichten LA, Rivera S, et al. Interleukin-6 regulates the zinc transporter Zip14 in liver and contributes to the hypozincemia of the acute-phase response. Proc Natl Acad Sci USA. 2005;102:6843-8.

25. Rambod M, Kovesdy CP, Kalantar-Zadeh K. Combined high serum ferritin and low iron saturation in hemodialysis patients: the role of inflammation. Clin J Am Soc Nephrol. 2008;3:1691-701.

26. Tonelli M, Sacks F, Pfeffer M, Jhangri GS, Curhan G. Biomarkers of inflammation and progression of chronic kidney disease. Kidney Int. 2005;68: 237-45.

27. Arici M, Walls J. End-stage renal disease, atherosclerosis, and cardiovascular mortality: is C-reactive protein the missing link? Kidney Int. 2001;59:407- 14.

28. Tang WW, Feng L, Vannice JL, Wilson CB. Interleukin-1 receptor antagonist ameliorates experimental anti-glomerular basement membrane antibody- associated glomerulonephritis. J Clin Invest. 1994;93:273-9.

29. Lan HY, Yang N, Metz C, et al. TNF-alpha up-regulates renal MIF expression in rat crescentic glomerulonephritis. Mol Med. 1997;3:136-44.

30. Stankovic-Popovic V, Nesic V, Popovic D, et al. Effects of conventional versus biocompatible peritoneal dialysis solutions on peritoneal and systemic inflammation, malnutrition and atherosclerosis in CAPD patients. Clin Nephrol. 2011;76:314-22.

31. Avram MM, Fein PA, Rafiq MA, Schloth T, Chattopadhyay J, Mittman N. Malnutrition and inflammation as predictors of mortality in peritoneal dialysis patients. Kidney Intern. 2006;70:S4-7.

32. Baradaran A, Nasri H. Association of serum C-reactive protein (CRP) with some nutritional parameters of maintenance hemodialysis patients. Pak J Nutr. 2005;4: 175-82.

33. Wratten ML, Tetta C, Ursini F, Sevanian A. Oxidant stress in hemodialysis: prevention and treatment strategies. Kidney Int. 2000;76:S126-32.

34. Xu Y, Zhang Z, Hu J, et al. Glucose-6-phosphate dehydrogenase-deficient mice have increased renal oxidative stress and increased albuminuria. FASEB J. 2010;24: 609-16.

35. Sharma A, Gadepally P. Nutritional therapy to attenuate inflammation in HD patients: fact or fiction? Nephrol News Issues. 2010;24:26-9.

36. Aranha LN, Lobo JC, Stockler-Pinto MB, Leal VD, Torres JP, Mafra D. Relationship between zinc levels and plasma leptin in hemodialysis patients. J Trace Elem Med Biol. 2012; [Epub ahead of print]. 
37. Sahin H, Uyanik F, Inanç N, Erdem O. Serum zinc, plasma ghrelin, leptin levels, selected biochemical parameters and nutritional status in malnourished hemodialysis patients. Biol Trace Elem Res. 2009;127:191-9.

38. Ghaemmaghami J, Mahdavi R, Faramarzi E, Mohammadpour N, Argani H. Does zinc supplementation improve dietary intake, symptoms of eating problems, and serum zinc levels in hemodialysis patients? Dial Transplant. 2010;39:530-3.

39. Knerr K, Füth R, Hemsen $P$, et al. Chronic inflammation and hemodialysis reduce immune competence of peripheral blood leukocytes in end-stage renal failure patients. Cytokine. 2005;30:132-8.

40. Ozdemir E, St John LS, Gillespie G, et al. Cytomegalovirus reactivation following allogeneic stem cell transplantation is associated with the presence of dysfunctional antigen-specific CD8+ T cells. Blood. 2002;100: 3690-7.

41. Wang HH, Lin CY, Huang TP. Patterns of CD4/CD8 T-cell ratio in dialysis effluents predict the long term outcome of peritonitis in patients undergoing peritoneal dialysis. Nephrol Dial Transplant. 2003;18:1181-9.

42. Haase H, Rink L. The immune system and the impact of zinc during aging. Immun Ageing. 2009;6:9.

43. Wintergerst ES, Maggini S, Hornig DH. Contribution of selected vitamins and trace elements to immune function. Ann Nutr Metab. 2007;51:301-23.

44. Zhang K, Liu L, Cheng X, Dong J, Geng Q, Zuo L. Low levels of vitamin $C$ in dialysis patients is associated with decreased prealbumin and increased C-reactive protein. BMC Nephrol. 2011;12:18.

45. Bunk MN, Dnistrian AM, Schwartz MK, Rivlin RS. Dietary zinc deficiency decreases plasma concentrations of vitamin E. Proc Soc Exp Biol Med. 1989;190:379-84.

46. Ashfaq MK, Zuberi HS, Anwar Waqar M. Vitamin E and beta-carotene affect natural killer cell function. Int J Food Sci Nutr. 2000;51 Suppl:S13-20.

47. Ha TK, Sattar N, Talwar D, et al. Abnormal antioxidant vitamin and carotenoid status in chronic renal failure. QJM. 1996;89:765-9. 